\title{
Placenta - a silent witness: clinical and forensic importance of placental examination
}

\author{
Marina Kos
}

Clinical Department of Pathology "Ljudevit Jurak" Clinical Hospital Center "Sestre milosrdnice”, Zagreb, Croatia

University of Zagreb Medical School. Zagreb, Croatia

\section{Introduction}

There is no doubt that obstetrics carries high medical liability risk. In many countries, gynecologists-obstetricians who attend childbirths and perform complex obstetric procedures are faced with increasing malpractice insurance premiums and litigation risk. The American College of Obstetricians and Gynecologists (ACOG) publishes its Survey of Professional Liability since 1983, with the objective to analyze the effect that malpractice litigation has had on the practice of obstetrics and gynecology in the United States ${ }^{1}$. According to the 2003 ACOG survey, $76.3 \%$ of the members who answered the questionnaire have been involved in a lawsuit at least once in their professional career; gynecologists/obstetricians have been sued a total of 2.64 times per individual over the course of their careers ${ }^{1,2}$. In the 2006 ACOG Survey, $89 \%$ of respondents indicated that they had been sued during their careers. The average number of claims per obstetrician was 2.6 (3). The ACOG's 2009 Survey on Professional Liability showed that nearly 91\% of gynecologists/obstetricians had experienced at least one liability claim filed against them during their professional careers, with an average of 2.69 claims per physician. In $2009,62 \%$ percent of the total reported claims were for obstetric care as opposed to gynecology, the same as in the 2006 Survey $^{3,4}$. In the 2003 ACOG survey, fetal monitoring, neurologically impaired children, neonatal death, shoulder dystocia, uterine rupture, and "decision-to-incision" time were identified as clinical factors frequently present in obstetric malpractice cases ${ }^{1}$. In both 2006 and 2009 Surveys the reasons for claim were neurologically impaired infant (in 31\% of cases in both Surveys), stillbirth/neonatal death (with $16 \%$ of cases in both Surveys), and delay or failure in diagnosis (in 11\% of cases in 2009 vs. $14 \%$ in 2006$)^{3,4}$.

In all the Surveys, neurological impair is the leading cause of the reasons for liability claim, with the cerebral palsy being the most serious damage. The possible etiologies have been discussed for years, and although the damage to neural tissue is undebatable, there is still no agreement upon the timing of the damage. Some authors think that $90 \%$ of the cases of cerebral palsy are not due to intrapartum events, while in the opinion of others most of the devastating events occurred in the perinatal period ${ }^{5,6}$. It is still impossible to firmly determine in each single case whether the hypoxic insult has developed during delivery, in the first few hours after birth, or was already present before the labor began, as a consequence of long lasting hypoxia during pregnancy.

Careful gross and histopathological examination of the placenta in chosen cases can elucidate the events that occurred some time before labor, and help to connect and reconstruct the course of disease $\mathrm{e}^{7,8}$.

\section{Importance of pathological examination of the placenta}

Today, it is undisputable that all the samples of diagnostic value removed from the human body should be histologically examined, with only a few exceptions, one of them being the healthy human placenta. The placenta forms a functional unit between the mother and the fetus and any pathological event that concerns one ore both of them will influence the normal function of the placenta, resulting sometimes in morphological gross and/or histological change(s). It is the most important fetal organ because it is responsible for exchange of all nutrients, oxygen, and fluid from mother to fetus and removal of fetal waste products. It has also been called the "diary of gestational life" 9 . The placenta provides important information's on the timing and 
etiology of many adverse events, including neurologic injury, fetal distress, infections, growth restriction, demise and many other fetal conditions. It also reflects the intrauterine environment, helps in identification of unsuspected maternal disorders, such as lupus or maternal vascular disease, and primary placental disorders, such as maternal floor infarction or chronic villitis. Furthermore, the placenta, being a fetal organ, expresses the fetal genotype and thus may provide diagnostic information on various genetic, chromosomal, congenital metabolic, or hematologic disorders ${ }^{10}$.

Severe abnormalities of the placenta may lead to adverse fetal outcome. Fortunately, the vast majority of pregnancies and newborns are normal, so only a subset of placentas requires submission to the pathology department for gross and histological examination. However, the clinical indications for placental examination have no gold standards. Some organizations have offered more or less similar guidelines, but the choice whether the placenta will be sent for histopathological examination is still left to the attending obstetrician.

\section{Indications for pathological examination of the placenta}

According to the guidelines issued by College of American Pathologists at their XIX Conference dedicated exclusively to the examination of the placenta and some other considerations, the main indications for placental examination are shown in Table 1.11,12

\begin{tabular}{|c|c|c|}
\hline Maternal conditions & Fetal conditions & Placental conditions \\
\hline $\begin{array}{l}\text { Systemic disorders (e.g. diabetes } \\
\text { mellitus, hypertensive disorders, } \\
\text { collagen vascular disease) }\end{array}$ & Stillbirth/neonatal death & $\begin{array}{c}\text { Abnormalities of the placental } \\
\text { shape }\end{array}$ \\
\hline $\begin{array}{l}\text { Unexplained third-trimester } \\
\text { bleeding }\end{array}$ & Multiple pregnancy & Retroplacental hematoma \\
\hline Severe oligohydramnios & $\begin{array}{l}\text { Congenital malformations, } \\
\text { dysmorphic phenotype or } \\
\text { abnormal karyotype }\end{array}$ & $\begin{array}{l}\text { Small or large placental size or } \\
\text { weight for gestational age }\end{array}$ \\
\hline Peripartum fever and/or infection & Intrauterine growth restriction & $\begin{array}{l}\text { Abnormalities of the umbilical } \\
\text { cord (length, appearence) }\end{array}$ \\
\hline Premature delivery & Prematurity & $\begin{array}{c}\text { Abnormalities of the fetal } \\
\text { membranes (e.g. amnion } \\
\text { nodosum, meconium staining, } \\
\text { etc) }\end{array}$ \\
\hline Drug addiction/alcochol abuse & Hydrops & \\
\hline $\begin{array}{l}\text { Invasive procedures with } \\
\text { suspected placental injury }\end{array}$ & Meconium & \\
\hline \multirow[t]{4}{*}{ Placental abruption } & $\begin{array}{l}\text { Admittance to neonatal intensive } \\
\text { care unit }\end{array}$ & \\
\hline & Apgar $<=3$ in 5 . minute & \\
\hline & Neurological problems (seizures) & \\
\hline & Suspected infection & \\
\hline
\end{tabular}

Table 1. The main indications for placental examination (modified from ref. 11, 12) 
Others recommend that placentas from pregnancy complicated with cholestasis, hepatitis B, human immunodeficiency infection, other maternal diseases with normal pregnancy outcome, placenta previa and postpartum hemorrhage should not be sent for pathological examination in spite of moderate cost of this examinati$\mathrm{on}^{13}$. These and other guidelines are only recommendations, and each institutions may accept all or only some of them, to meet the needs of the population they serve.

Even with valid indications the human placenta is one of the most under examined specimens. However, all placentas should be examined grossly, immediately after delivery, by the attending physician or a nurse. To conclude whether the placenta is normal, or should be sent for pathological examination, the person examining the placenta should have at least a basic knowledge of placental anatomy and pathology. The description of the placental shape, the color of the fetal membranes, the insertion and length of the umbilical cord and placental weight must be recorded in the clinical history. Even though the placenta should be left suspended on the umbilical cord for at least an hour after delivery, this practice is never followed, so the placental weight measured immediately after delivery is about 10 to $20 \%$ greater than the real weight because of the blood it contains $^{8}$. No matter the indications that are followed, the chosen placentas are sent to the pathology department.

Placentas submitted to pathological examination should be accompanied by a specimen requisition form containing clinical information. The importance of providing the clinical information cannot be overemphasized, because the absence of clinical informations prevents the appropriate evaluation and hampers the conclusions that are drawn from it. The informations that must be included are gravidity and parity, obstetric history, obstetric estimate of gestational age, route of delivery, fetal birth weight, gender, Apgar scores, maternal and fetal complications of pregnancy, labor, delivery, and total umbilical cord length. Some institutions even have a dedicated specimen requisition form for the placenta that facilitates the provision of these informations to the pathologist. The clinician should also state the indication(s) for which the placenta is being submitted ${ }^{14}$.

The obstetricians should bear in mind that in case bacterial or/and viral cultures, cytogenetic and metabolic studies are needed the samples must be taken from the fresh placental tissue and in sterile conditions, immediately after delivery, in the delivery room. Depending on a pathologist that is going to examine the placenta, it can be submitted fresh, without fixative, or in the appropriate amount (10 times placental volume) of fixative, usually $10 \%$ buffered formalin. If there is no possibility of the pathological examination of the placenta in the near future, or a delay is anticipated between delivery and receipt at the pathology department the placenta can be stored in a refrigerator at $4^{\circ} \mathrm{C}$ for a week. It would be ideal, but is practically impossible in most institutions, for all placentas not requiring pathological examination to be stored in a refrigerator for a week in case the clinical status of the newborn changes, so that the placenta can still be pathologically examined. The placenta should never be deep frozen, because the ice crystals distort the villi, and the fine pathological changes are impossible to appreciate on histological examination ${ }^{8}$.

\section{Pathological evaluation and reporting}

The fact of life is that in most pathological departments, other biopsies have precedence over placentas, so the obstetrician often receives the report on a placenta several weeks after submission. The report usually contains only placental measures and gross description of the placenta and the umbilical cord (frequently not even that) and the description of the histological appearance is ,immature placenta“" or "mature placenta“, or ,placenta without pathological changes“. After reading such reports, many obstetricians that are not convinced in the usefulness of the placental pathological examination in the first place, are discouraged to continue seeking pathological consultation. Placental lesions associated with adverse perinatal outcome can be roughly divided into those with abnormal blood flow in the maternal circulation, abnormal blood flow in the fetal circulation, inflammatory processes, and primary placental lesions ${ }^{8,10}$. Each of these categories is associated with identifiable pathologic lesions. Intrauterine demise or neurologic injury can occur by sudden and possibly devastating events, by chronic processes that lead to decreased placental and fetal reserves, or by a combination of both. It is helpful to distinguish between pathologic placental lesions that result in acute and chronic intrauterine compromise (Table 2.) $)^{15}$

14. Kongres udruženja patologa i citologa Srbije sa međunarodnim učešćem, Beograd 14-16 juna, 2012

14 th Congress of Serbian Association of Pathologists and Cytologists with international participation, Belgrade 14-16 June, 2012 


\begin{tabular}{|l|}
\hline Acute \\
\hline Normal placental weight or weight appropriate for fetal weight \\
\hline Acute villous edema \\
\hline Intravillous hemorrhage \\
\hline Acute retroplacental hemorrhage \\
\hline Acute meconium staining \\
\hline Chronic \\
\hline Abnormal placental weight in relation to fetal weight \\
\hline Chorangiosis \\
\hline Fetal normoblastemia \\
\hline Chronic meconium staining \\
\hline Meconium associated myonecrosis of cord vessel(s) \\
\hline Acute or necrotising funisitis \\
\hline Significant chronic villitis \\
\hline Amnion nodosum \\
\hline Significant placental ischemia or infarction \\
\hline Decidual vasculopathy \\
\hline Maternal floor infarction/massive perivillous fibrinoid deposition \\
\hline Fetal thrombotic vasculopathy \\
\hline
\end{tabular}

Table 2. Placental findings indicating acute and chronic in utero compromise ${ }^{15}$

The quality of reports on the investigation of the placenta also varies greatly from institution to institution. One study showed that general surgical pathologists have a higher rate of under diagnosis of placental lesions compared to pediatric pathologists ${ }^{16}$. These findings underline the fact that the reporting pathologist should be adequately trained and experienced in placental pathology. Templates and checklists for the reporting of placentas might help to improve the completeness and uniformity of reporting ${ }^{17}$. The pathological report on placenta is usually sent only to the attending obstetrician, while the neonatologists or pediatricians caring for a newborn are not aware of the findings. In the opinion of the author, the copy of the placental pathology report should be filed in both the mother's and newborn's clinical history.

\section{Discussion}

Of the ACOG Survey respondents who reported making changes to their obstetric practice as a result of the risk or fear of professional liability claims or litigation, 30\% decreased the number of high-risk obstetric patients that they accepted. Performing more cesarean sections was reported by $29 \%$ of respondents that changed their obstetric practices, and $25.9 \%$ stopped offering/performing vaginal births after cesarean (VBACs). An additional $13.9 \%$ decreased the number of total deliveries. About $8 \%$ of survey respondents reported that they had stopped practicing obstetrics altogether ${ }^{4}$.

Other studies addressing this problem showed that malpractice claims led to a small reduction in physician delivery volume, but they did not have a significant impact on cesarean section rates ${ }^{18,19}$. Litigation risk 
and high malpractice premiums certainly affect negatively the gynecologist-obstetricians' career satisfaction. The result of a relatively recent study revealed that $43.7 \%$ of gynecologist-obstetricians had become less satisfied over the last 5 years and $34.0 \%$ would not recommend obstetrics/gynecology to students seeking career advice ${ }^{20}$.

Gynecologists/obstetricians are not the only doctors involved in delivery that are sued very frequently. Anesthesiologists, and pediatricians/neonatologists are also often accused of malpractice in cases of unfavorable outcome of pregnancy. Before 1990 maternal death and newborn death/brain damage were the most common complications in obstetric anesthesia malpractice claims. Newborn death/brain damage has decreased, yet it still remains also a leading cause of obstetric anesthesia malpractice claims ${ }^{21}$.

The basis of litigation claims against obstetricians, anesthesiologists and neonatologists is the notion that fetal death or neurological disabilities are the result of failure or delay in intervention or inappropriate management of injuries believed to have occurred during the process of delivery. The intense fetal monitoring and changes in methods of delivery have decreased the incidence of cerebral palsy, but not substantially $22-24$. One of the reasons for this is that most of the fetal brain injuries occur before hospital admission and the beginning of labor, many of them being the result of intrauterine infection and inflammation, or reduced or interrupted placental vascular perfusion ${ }^{25}$ ). The majority of cases of cerebral palsy, particularly in term infants, are now considered to be due to ante partum events ${ }^{26,27}$.

In the context of stillbirth or neurological impairment, examination of the placenta may be helpful in several ways. Firstly, the placenta itself may be abnormal and contribute directly to the adverse outcome, (e.g. when there is a tight umbilical cord knot, maternal floor infarction or a large chorangioma). The category of primary placental lesions also contains massive perivillous fibrinoid deposition, decidual vasculopathy leading to placental ischemia and/or infarction. Placenta itself may sometimes function normally, but the pathologic findings reflect abnormal intrauterine environment (e.g. intervillous thrombosis in a pale and hydropic placenta whose villous capillaries contain nucleated fetal red blood cells that reflects fetomaternal hemorrhage). Some findings (such as chorangiosis) reflect an adaptation to adverse intrauterine conditions (hypoxia). The adverse outcome may be due to pathologic processes that are not placental in origin but that lead to abnormal placental function such as maternal under perfusion and fetal thrombotic vasculopathy. .Many placental lesions develop during the prenatal period, long before labor and delivery. They cannot be prevented even by the best of obstetrical care, but they can be identified and documented by pathological examination of the placenta ${ }^{28}$. In case of adverse pregnancy outcome, the normal placental findings on pathological examination are also very important, because in such a case certain conditions may be ruled out and the attention should be directed elsewhere to look for the cause of injury.

During legal proceedings, the pathologist functioning as an expert witness may be asked to specify a time frame for a placental lesion. It is often impossible to provide answers accurate to days or hours, but the rough distinction and framework of placental pathologies that result in acute or chronic compromise can be used for determining the timing of the fetal insult. Pathologic examination provides more information on chronic than on acute events. However, many acute events can also be diagnosed or confirmed on placental examination. Acute lesions may be associated with sudden catastrophic events whereas chronic lesions develop over a period of time leading to decreased placental reserves at a minimum. Markedly depleted reserves will render the infant susceptible to stresses of labor and to more acute events and therefore may also be associated with significant injury or death. In stillborn or neurologically impaired infants, multiple placental lesions are often present. By the timing of all lesions found, a sequence of events can be reconstructed in the development of an adverse intrauterine environment. The decrease of placental reserves and function is usually the result of synergistic action of multiple lesions of different etiologies that involve different aspects of placental function (fetal or maternal blood circulation). Acute events also frequently occur in combination with chronic processes $^{29}$. Multiple placental lesions greatly increase the susceptibility of the fetus to neurologic damage ${ }^{29-31}$.

The type and significance of placental lesions determine the extent to which placental pathology can be helpful in understanding adverse antenatal and perinatal events. Interpretation of these lesions is complex and requires experience and insight into clinicopathologic correlation with outcome. However, the most important part of placental examination is ensuring that it is performed, because the slides and paraffin blocks of

14. Kongres udruženja patologa i citologa Srbije sa međunarodnim učešćem, Beograd 14-16 juna, 2012

14 th Congress of Serbian Association of Pathologists and Cytologists with international participation, Belgrade 14-16 June, 2012 
placental tissue remain in the archives and can be retrieved even after a couple of years, should the need for revision or expertise arise. A photographic record of gross pathologic findings is also very useful. The gross and histological pathologic report of the placenta may not completely explain the etiology and timing but is an important and essential witness in understanding adverse pregnancy outcome. One also has to bear in mind that placental lesions are not necessarily the cause of unfavorable pregnancy outcome, and some structural changes may be the consequences of poor fetal condition. The placenta is an easily available specimen and the costs of a routine pathological examination are moderate, so in all doubtful cases, the clinicians should not hesitate to ask for a pathological analysis and opinion.

\section{References}

1. Strunk AL, Esser L. Overview of the 2003 ACOG Survey of Professional Liability. ACOG Clinical Review. 2004; 9:1;13-6.

2. American College of Obstetricians and Gynecologists. Survey of professional liability. Washington, DC: American College of Obstetricians and Gynecologists; 2003;.

3. Chervenak JL. Overview of professional liability. Clin Perinatol 2007; 34:227-32

4. http://www.theunnecesarean.com/blog/2009/9/11/acog-releases-survey-results-ob-gyns-ultimately-hurt-patient.html

5. Maclennan A. A template for defining a causal relation between acute intrapartum events and cerebral palsy: international consensus statement. BMJ 1999; 319:1054-9

6. Cowan R, Rutherford M, Groenendaal F, et al. Origin and timing of brain lesions in term infants with neonatal encephalopathy. Lancet 2003; 361:736-42.

7. d'Aloja E, Müller M, Paribello F, Demontis R, Faa A. Neonatal asphyxia and forensic medicine. J Matern Fetal Neonatal Med. 2009; 22:54-6.

8. Kos M, Leniček T. Osnove patologije posteljice. Medicinska Naklada, Zagreb, 2011.

9. Altshuler G. Some placental considerations in alleged obstetrical and neonatology malpractice. In: Wecht CH, editor. Legal medicine. Salem (NH): Butterworth Legal Publishers; 1994. p.27-47.

10. Baergen RN. The Placenta as Witness. Clin Perinatol 2007; 34:393-407.

11. Altshuler G, Deppisch LM .College of American Pathologists Conference XIX on the Examination of the Placenta: report of the Working Group on Indications for Placental Examination. Arch Pathol Lab Med. 1991; 115:701-3.

12. Langston C, Kaplan C, Macpherson T, et al. Practice guideline for examination of the placenta: developed by the Placental Pathology Practice Guideline Development Task Force of the College of American Pathologists. Arch Pathol Lab Med 1997; 121:449-76

13. B Hargitai, T Marton, P M Cox. Examination of the human placenta. J Clin Pathol 2004; 57:785-792

14. Bull AD, Cross SS, James DS, Silcocks PB. Do pathologists have extrasensory perception? BMJ 1991; 303:1604-5.

15. Chang KTE. Pathological examination of the placenta: Raison d'être, clinical relevance and medicolegal utility. Singapore Med J 2009; 50:1123-33.

16. Sun CC, Revell VO, Belli AJ, Viscardi RM. Discrepancy in pathologic diagnosis of placental lesions. Arch Pathol Lab Med 2002; 126:706-9.

17. Khong TY, Gordijn SJ. Quality of placental pathology reports. Pediatr Dev Pathol 2003; 6:54-8.

18. Gimm GW. The impact of malpractice liability claims on obstetrical practice patterns. Health Serv Res 2010; 45:195-211. 
19. Grant D, McInnes MM. Malpractice experience and the incidence of cesarean delivery: a physician-level longitudinal analysis. Inquiry $2004 ; 41: 170-8$.

20. Xu X, Siefert KA, Jacobson PD, Lori JR, Ransom SB The impact of malpractice burden on Michigan obstetriciangynecologists' career satisfaction. Womens Health Issues 2008; 18:229-37.

21. Davies JM, Posner KL, Lee LA, Cheney FW, Domino KB. Liability associated with obstetric anesthesia: a closed claims analysis. Anesthesiology 2009; 110:131-9.

22. Scheller JM, Nelson KB. Does cesarean delivery prevent cerebral palsy or other neurologic problems of childhood? Obstet Gynecol 1994; 83:624-30.

23. Winter S, Autry A, Boyle C, Yeargin-Allsopp M. Trends in the prevalence of cerebral palsy in a population-based study. Pediatrics 2002; 110:1220-5.

24. Nelson KB. Can we prevent cerebral palsy? N Engl J Med 2003; 349:1765-9.

25. Nelson KB, Grether JK. Causes of cerebral palsy. Curr Opin Pediatr 1999; 11:487-91.

26. Kuban KC, Leviton A. Cerebral palsy. N Engl J Med 1994; 330:188-95.

27. Cowan R, Rutherford M, Groenendaal F, et al. Origin and timing of brain lesions in term infants with neonatal encephalopathy. Lancet 2003; 361:736-42.

28. Ward CJ. Analysis of 500 obstetric and gynecologic malpractice claims: causes and prevention. Am J Obstet Gynecol 1991; 165:298-304; discussion 304-6.

29. Redline RW, O'Riordan A. Placental lesions associated with cerebral palsy and neurologic impairment following term birth. Arch Pathol Lab Med 2000;124:1785-91.

30. Redline RW. Severe fetal placental vascular lesions in term infants with neurologic impairment. Am J Obstet Gynecol 2005;192:452-7

31. Viscardi RM, Sun CJ. Placental lesion multiplicity: risk factor for IUGR and neonatal cranial ultrasound abnormalities. Early Hum Dev 2001;62:1-10. 